From the behavioural analysis of circuits and the timing analysis of the simulations carried out in the study the following conclusions can be made:

(1) The design parameters of MTJ-MRAM show better performance in terms of delay, showing in femtoseconds exhibiting three time delay reduction in both 45 and $90 \mathrm{~nm}$ designs when compared to flash memory circuit.

(2) The design exhibits significant power reduction of about six times compared to SRAM memory circuit in both 45 and $90 \mathrm{~nm}$ technology. While the MTJ-MRAM design in $45 \mathrm{~nm}$ technology experiences a bottleneck in terms of power dissipation.

(3) The behavioural characteristics of MTJ-MRAM show non-volatility feature. Designing the memory circuit for FPGA architecture, the configuration time of FPGA decreases and speeds up the overall FPGA process with the added advantage of minimized power consumption compared to SRAM-based FPGA.

1. Hamsa, S., Ananth, A. G. and Thangadurai, N., A study of semiconductor memory technology by comparing volatile and nonvolatile memories. J. Adv. Res. Dyn. Control Syst., 2018, 10(4), 1252-1258.

2. Chakraverty, M. et al., First principle simulations of various magnetic tunnel junctions for applications in magnetoresistive random access memories. IEEE Trans. Nanotechnol., 2013, 12(6), 971977

3. Choi, D. et al., New non-volatile memory structures for FPGA architectures. IEEE Transactions Very Large Scale Integr. Syst., 2008, 16(7), 874-881

4. Islam, A., Rajan, N. S. and Dwivedi, A. K., Compact design of an MTJ-based non-volatile CAM cell with read/write operations. Microsyst. Technol., 2018, pp. 1-12.

5. Endoh, T., Koike, H., Ikeda, S., Hanyu, T. and Ohno, H., An overview of nonvolatile emerging memories-spintronics for working memories. IEEE J. Emerg. Sel. Top. Circuits Syst., 2016, 6, 109-119.

6. Kim, K. and Yoo, C., Macro model of magnetic tunnel junction for STT-MRAM including dynamic behavior. J. Semicond. Technol. Sci., 2016, 14(6), 728-732.

7. $\mathrm{Hu}, \mathrm{G}$. et al., MRAM with double magnetic tunnel junctions. In IEEE International Electron Devices Meeting, Hsinchu, 2015, pp. 668-671.

8. Peng, S. et al., Magnetic tunnel junctions for spintronics: principles and applications. In Wiley Encyclopedia of Electrical and Electronics Engineering (ed. Webster, J.), 2014, pp. 1-16.

9. Huet, G. et al., Low-current spin transfer torque MRAM. Nature Nanotechnol., 2017, 10(3), 187-191.

10. Hamsa, S. et al., Low power device design application by magnetic tunnel junctions in magnetoresistive random access memory [MRAM]. SN Appl. Sci., 2019, 1(8), 1-7.

11. Wolf, S. A. et al., Spintronics: a spin-based electronics vision for the future. Science, 2001, 294, 1488-1495.

12. Prejbeanu, I. L. et al., Thermally assisted MRAM. J. Phys.: Condens. Matter, 2007, 19(16), 165218.

13. Nozieres, J., Dieny, B., Redon, O., Sousa, R. and Prejbeanu, I., Magnetic memory with a magnetic tunnel junction written in a thermally assisted manner, and method for writing the same. US 2006/0291276, A1, 28 December 2006, pp. 1-8.

14. Worledge, D. C. et al., Theory of spin torque switching current for the double magnetic tunnel junction. IEEE Magn. Lett., 2017, 8, $1-15$.
15. Slonczewski, J. C., Current-driven excitation of magnetic multilayers. J. Magn. Magn. Mater., 1996, 159(1), L1-L7.

16. Berger, L., Emission of spin waves by a magnetic multilayer traversed by a current. Phys. Rev. B., 1996, 54, 9353-9358.

17. Deak, J., Thermo-magnetically assisted spin-momentum-transfer switching memory. EP Patent App. EP20,050,805,862, 2008.

18. Liu, L. et al., Current induced switching of perpendicularly magnetized magnetic layers using spin torque from the spin Hall effect. Phys. Rev. Lett., 2012, 109, 096602.

19. Liu, L., Pai, C.-F. and Li, Y., Spin-torque switching with the giant spin Hall effect of tantalum. Science, 2012, 336, 555-558.

Received 22 February 2019; revised accepted 11 February 2020

doi: $10.18520 / \mathrm{cs} / \mathrm{v} 119 / \mathrm{i} 1 / 119-123$

\section{Sterically hindered amine functionalized zeolites prepared from fly ash for effective carbon dioxide adsorption}

\author{
Arti Valechha ${ }^{1, *}$, Sunit Kumar Singh ${ }^{1}$, \\ Ahmed Sadeq Al-Fatesh ${ }^{2}$, Sadhana Rayalu ${ }^{3}$ and \\ Nitin Labhsetwar ${ }^{1}$
}

${ }^{1}$ Energy and Resource Management Division, CSIR-National Environmental Engineering Research Institute, Nehru Marg, Nagpur 440 020, India

${ }^{2}$ Chemical Engineering Department, College of Engineering,

King Saud University, P.O. Box 6800, Riyadh 11421,

Kingdom of Saudi Arabia

${ }^{3}$ Environmental Materials Division, CSIR-National Environmental

Engineering Research Institute, Nehru Marg, Nagpur 440 020, India

Highly crystalline zeolite $\mathrm{Na}-\mathrm{X}$ also known as Linde $\mathrm{X}$, is synthesized in pure form using fly ash waste from coal-fired power plants. Functionalization of assynthesized adsorbent was carried out using 2-amino2-methyl-1-propanol in order to apply it in postcombustion carbon dioxide capture. Zeolite $\mathrm{Na}-\mathrm{X}$ was thoroughly characterized through XRD, FTIR, SEM and TEM analysis. The synthesized zeolite was found to have high surface area and octahedral morphology. Zeolite $X$ and functionalized zeolite $X$ were evaluated in a dynamic adsorption assembly for the uptake of carbon dioxide. Functionalized zeolite was found to have better adsorption capacity at $55^{\circ} \mathrm{C}$. It also showed good performance in the presence of moisture. Regeneration studies, however, showed a drop after the second cycle in case of functionalized adsorbent.

Keywords: Amine functionalization, adsorbent, carbon dioxide, fly ash, zeolites.

*For correspondence. (e-mail: artivalechha@rediffmail.com) 
THE concentration of carbon dioxide in the atmosphere exceeded $400 \mathrm{ppm}$ in the year 2018-19. The rising levels of $\mathrm{CO}_{2}$ are mainly due to swift industrialization, increasing energy consumption, modern civilization and rapidly increasing transport ${ }^{1,2}$. These $\mathrm{CO}_{2}$ emissions are believed to be primarily responsible for global warming. Scientists worldwide are finding ways for control, conversion and possible utilization of $\mathrm{CO}_{2}$ into valuable products. Three main technologies are available for carbon capture and sequestration, which include pre-combustion, postcombustion and oxy-fuel combustion ${ }^{3,4}$. As a retrofit option, post-combustion is considered appropriate for existing thermal power plants. Both absorption and adsorption are explored extensively to capture $\mathrm{CO}_{2}$ from point sources, where emission is in the range $4-15 \% \mathrm{CO}_{2}$. However, adsorption has some advantages over absorption, for example, in the absorption process problems associated with corrosion of the reactor, toxicity, and high cost for regeneration are yet to be addressed. In the post-combustion approach, selective adsorption of $\mathrm{CO}_{2}$ using suitable adsorbents is envisaged as a good alternative for carbon capture and sequestration due to easy regeneration of adsorbent through temperature and pressure manipulations. However, the crux of the research lies in the development of an adsorbent with economic feasibility, high $\mathrm{CO}_{2}$ selectivity with good adsorption capacity and having excellent regeneration ability. In this context, zeolite which is an inorganic and porous material, is identified as one of the obvious choices due to its high surface area and selectivity towards $\mathrm{CO}_{2}$ capture.

Fly ash, an industrial by-product of coal-fired power plants rich in minerals containing silica and alumina has a production rate of 420 million tonnes per year globally. It is considered as an environmental pollutant without any safe disposable option. Though a part of the fly ash produced is used as an additive in cement, embankment, land-filling and other construction products, major portion of fly ash still remains unutilized ${ }^{5,6}$. It is also considered as a potential precursor for synthesizing high value-added zeolite; converting fly ash into zeolite will not only reduce the problem of safe disposal of the former, but will also be a market asset. Reaction conditions for different types of zeolite synthesis have been optimized using fly ash ${ }^{7-15}$. The major concern in using zeolite for adsorption purpose is the decrease in capacity in the presence of moisture, which is a requisite condition for a flue gas stream. To facilitate adsorption at higher temperatures in the presence of moisture, we have functionalized zeolite synthesized from fly ash with a sterically hindered amine, viz. 2-amino-2-methyl-1-propanol (AMP). Bougie and Iliuta $^{16}$ have reviewed the use of AMP in an absorption process from flue gas streams over other alkanolamines like monoethanolamine (MEA), diethanolamine (DEA) and $N$-methyl diethanolamine (MDEA). They have concluded that AMP offer an added advantage of high absorption capacity, slower degrada- tion, faster kinetics and improved selectivity. Taking the mixed concept of absorption using AMP and adsorption of zeolite, we have functionalized fly ash zeolite (FAZ) with AMP and then applied it for adsorption of $\mathrm{CO}_{2}$.

In the present study, we have synthesized zeolite $\mathrm{Na}-\mathrm{X}$ Faujasite framework type (FAU) by an alkali fusion method, followed by hydrothermal crystallization. The resultant zeolite $\mathrm{Na}-\mathrm{X}$ obtained is highly crystalline with high surface area. Further, it was functionalized with AMP and used as an adsorbent for post-combustion $\mathrm{CO}_{2}$ capture. AMP-functionalized zeolite $\mathrm{Na}-\mathrm{X}$ efficiently adsorbs $\mathrm{CO}_{2}$ in the presence of moisture.

Fly ash used in this study was collected from Koradi Thermal Power Station (KTPS), Nagpur, Maharashtra, India. All the other reagents purchased were A.R.-grade, and were used without any further purification. Sodium hydroxide pellets, zeolite X, zeolite $13 \mathrm{X}$ and AMP were procured from E-Merck, India. HPLC-grade methanol was purchased from Qualigens India. DI water was used throughout the experiment.

Iron-based impurities were removed from fly ash mechanically using magnetic separation. Next, $10 \mathrm{~g}$ of iron-removed fly ash was milled with $12 \mathrm{~g}$ of $\mathrm{NaOH}$ in a mechanical mortar for $2 \mathrm{~min}$; the resultant mixture was then heated at $550^{\circ} \mathrm{C}$ for $1.5 \mathrm{~h}$. After cooling the mixture to room temperature, the solid mass was again crushed. To this mixture, $200 \mathrm{ml}$ of water was added, followed by commercial zeolite $\mathrm{X}$ for seeding. The slurry so obtained was kept for ageing overnight, followed by hydrothermal treatment for $12 \mathrm{~h}$ at $95^{\circ} \mathrm{C}$. The resultant solution was then washed several times until the filtrate $\mathrm{pH}$ was between 9 and 10. Finally, the synthesized zeolite was dried at $80^{\circ} \mathrm{C}$ in an oven (Figure 1). This was called fly ash

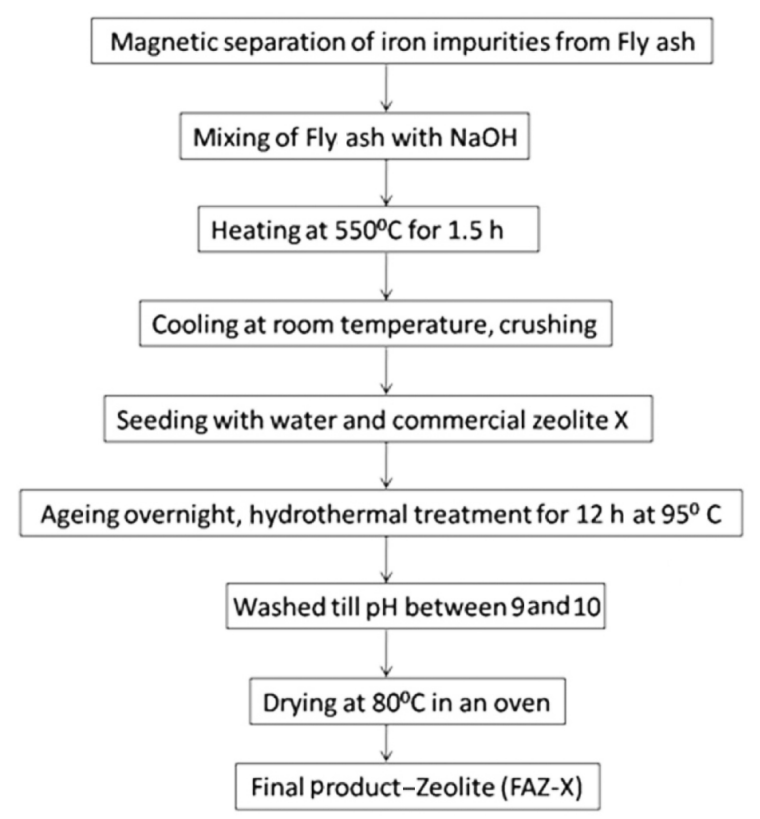

Figure 1. Schematic representation of the synthesis of zeolite FAZ-X. 
zeolite-X (FAZ-X). As-synthesized zeolite FAZ-X was functionalized with AMP by wet impregnation method. Powdered zeolite was wetted in methanol in a solid/liquid weight ratio of $1: 2$ for uniform loading. It was then kept for drying at room temperature for about $2 \mathrm{~h}$. Different $\%$ compositions of AMP prepared in methanol were mixed with zeolite FAZ-X, and then agitated on a rotary evaporator for $4 \mathrm{~h}$. Three different loadings were carried out and the corresponding zeolites were abbreviated as FAZ-AMP $x$, where $x$ denotes wt $\%$ AMP loaded on zeolite. FAZ-AMP10, FAZ-AMP25 and FAZ-AMP50 correspond to $10 \mathrm{wt} \%, 25 \mathrm{wt} \%$ and $50 \mathrm{wt} \%$ of AMP loading on FAZ-X.

$\mathrm{X}$-ray diffraction (XRD) analysis was performed using Rigaku Miniflex II Instrument. $\mathrm{Cu} \mathrm{K} \alpha$ radiation was used at $30 \mathrm{kV}$ and $15 \mathrm{~mA}$ with a monochromator. The XRD patterns were recorded from $10^{\circ}$ to $90^{\circ}$ ( $2 \theta$ range) at $2 \%$ min as scanning speed. Diffraction peaks were identified using the International Centre for Diffraction Data (ICDD) standard database. Nitrogen adsorption-desorption analysis of samples was performed using Micromeritics ASAP-2000 instrument. The isotherms were recorded at $-196^{\circ} \mathrm{C}$. For this analysis, samples were pretreated at $200^{\circ} \mathrm{C}$ for $6 \mathrm{~h}$. Brunauer, Emmett and Teller (BET) method was used for calculating the surface area of the samples. Barrett-Joyner-Halenda (BJH) method was applied for pore size-distribution analysis. High resolution transmission electron microscopy (HR-TEM) and scanning electron microscopy (SEM) were used for morphological and structural analysis respectively. JEOL JEM-3010 microscope operated at $300 \mathrm{kV}$ (LaB ${ }_{6}$ cathode, point resolution $1.7 \AA$ ) was used for HR-TEM analysis. SEM studies were performed on JEOL JSM-6380A instrument using $8 \mathrm{kV}$ accelerating voltage. $\mathrm{CO}_{2}$ adsorption capacity at equilibrium was also calculated using the Autosorb instrument at $0^{\circ} \mathrm{C}$.

The experimental set-up used consisted of mass flow controllers (Aalborg, USA) and a mixing chamber for the preparation of a simulated flue gas. A fixed mass $(0.5 \mathrm{~g})$ of moisture-free adsorbent was packed in a glass column with an inert filler material (glass beads). The adsorbent sample was then subjected to drying in an oven at $110^{\circ} \mathrm{C}$ for $3 \mathrm{~h}$. The glass column was placed in a temperaturecontrolled furnace. The sample was again subjected to pretreatment in helium flow $(20 \mathrm{ml} / \mathrm{min})$ for $6 \mathrm{~h}$ at $140^{\circ} \mathrm{C}$. This pretreatment was to ensure removal of any volatile contaminants and any pre-adsorbed gases present in the pores of the adsorbent. Subsequently, the adsorbent was cooled to desired operating temperature followed by exposure to $15 \%$ by volume of $\mathrm{CO}_{2}$ and balance $\mathrm{N}_{2}$ at a feed rate of $20 \mathrm{ml} / \mathrm{min}$. The effluents from the adsorbent column were analysed using gas chromatography. PerkinElmer gas chromatograph equipped with a thermal conductivity detector (TCD) and Porapak-Q packed column was used for this purpose. Figure 2 shows a schematic of the experimental set-up.
The XRD pattern of FAZ-X (Figure $3 c$ ) clearly depicts a highly crystalline and pure zeolite $\mathrm{NaX}$ with high intensity, indicating the successful formation of zeolite Na-X, also known as Linde $\mathrm{X}$ or zeolite $\mathrm{X}$. The XRD pattern was found to perfectly match with ICDD no. 00-0380237. The $2 \theta$ peaks at $10.00,15.40,23.30,26.60$ and 30.90 are characteristic peaks of zeolite with a faujasite structure $^{17,18}$, and these peaks are clearly observed in the synthesized FAZ-X. It was observed that there was no difference in XRD patterns of FAZ-X and FAZ-AMP10, FAZ-AMP25 and FAZ-AMP50. This suggests that the

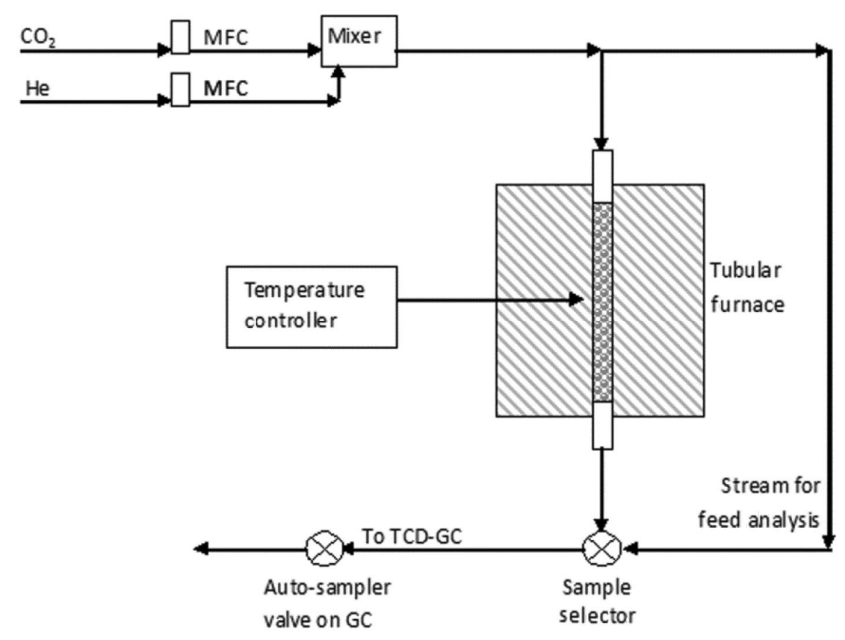

Figure 2. Schematic representation of experimental set-up for carbon dioxide adsorption.
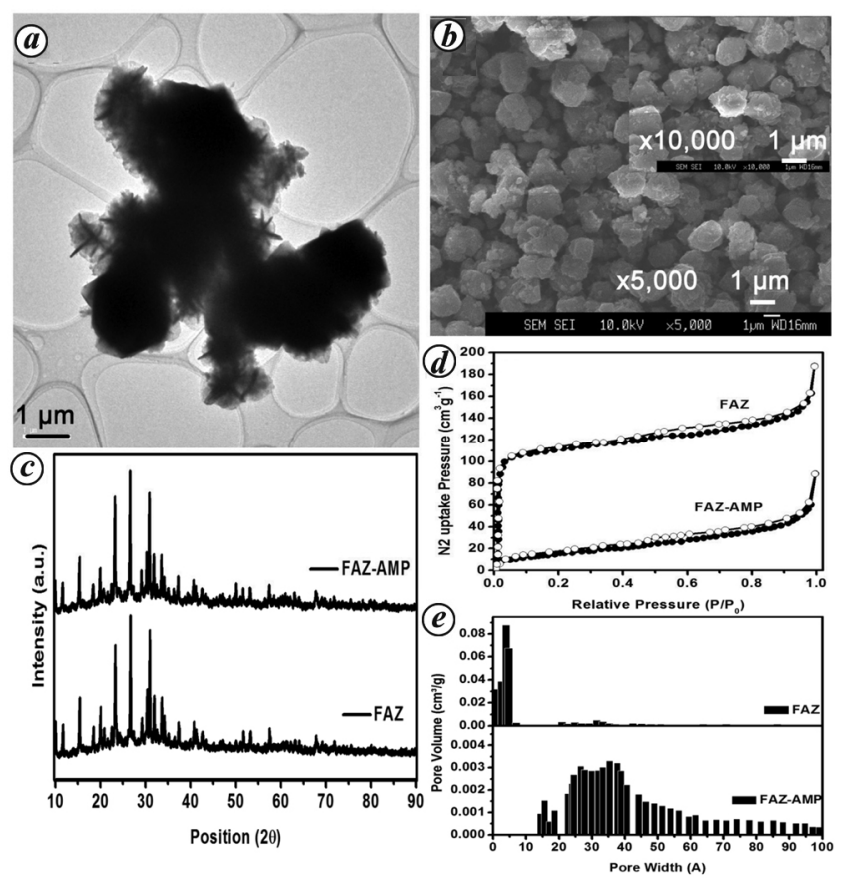

Figure 3. $\boldsymbol{a}$, TEM image of as-synthesized FAZ-X. $\boldsymbol{b}$, SEM images of as-synthesized FAZ-X. $\boldsymbol{c}$, PXRD pattern. $\boldsymbol{d}, \mathrm{N}_{2}$ adsorption isotherms of as-synthesized FAZ-X and FAZ-AMP25. $\boldsymbol{e}$, Pore size distribution of synthesized FAZ-X and FAZ-AMP25. 
structural integrity of the zeolite matrix has been retained even after the incorporation of sterically hindered amine. This is important, since structural stability of the adsorbent is essential after incorporation of bulky groups. $\mathrm{N}_{2}$ adsorption isotherm (Figure $3 d$ ) obtained for FAZ-X and FAZ-AMP25 can be classified as type I according to the IUPAC nomenclature ${ }^{19}$. This type of curve is mainly given by microporous materials. Increase in the adsorption at lower pressure is an indication of definite and uniform growth in the number of micropores in the synthesized adsorbent. Surface area of FAZ-X and FAZAMP25 was found to be 327.77 and $50.89 \mathrm{~m}^{2} / \mathrm{g}$ respectively. Decrease in surface area of the functionalized sample was mainly due to pore blockage or filling by a bulky amine group. Pore size-distribution graph of FAZ$\mathrm{X}$ (Figure $3 e$ ) reveals that the pores are formed with an average size of $1.26 \mathrm{~nm}$. The presence of less number of $3-5 \mathrm{~nm}$ pores was also observed from the pore size distribution. On the other hand, FAZ-AMP25 did not show a uniform pore size distribution (Figure $3 e$ ). It was concluded based on Figure $3 d$, that functionalization of zeolite with AMP leads to blockage of micropores of zeolite. This results in a sharp decline in $\mathrm{N}_{2}$ adsorption at low $P / P_{0}$. This was also reflected in the pore size distribution (Figure $3 e$ ), which showed only mesopores with wide distribution of pore size. Physical morphology of FAZ-X was observed through SEM and TEM analysis. TEM and SEM images (Figure $3 a$ and $b$ respectively) indicate that octahedral and discrete crystals are formed, which is in agreement with zeolite $\mathrm{Na}-\mathrm{X}$ as reported in the literature.

$\mathrm{CO}_{2}$ uptake on functionalized zeolites and many other porous materials is generally due to chemisorption and not ion-exchange. The basic molecules are considered for functionalization to attract acidic $\mathrm{CO}_{2}$. Therefore in the present study also, amine was selected for functionalization. Different AMP-based adsorbents were synthesized in methanol medium using various concentrations of AMP in the range $10 \mathrm{wt} \%, 25 \mathrm{wt} \%$ and $50 \mathrm{wt} \%$, to observe the effect of AMP concentration on the adsorption capacity of the material. Three AMP-impregnated FAZ-X adsorbents were evaluated for $\mathrm{CO}_{2}$ adsorption along with bare FAZ-X. The $\mathrm{CO}_{2}$ adsorption of these adsorbents was done at $75^{\circ} \mathrm{C}$, containing $15 \% \quad \mathrm{CO}_{2} / \mathrm{N}_{2}$ mixture (Figure $4 d) . \quad \mathrm{CO}_{2}$ adsorption capacity of FAZ-AMP50 was $20.35 \mathrm{mg} / \mathrm{g}$, which was lower than FAZ-AMP25 having adsorption capacity of $52.33 \mathrm{mg} / \mathrm{g}$. Thus with increasing AMP loading, more pore blockage is expected by the sterically hindered AMP molecules in case of FAZAMP50. Adsorption capacity of bare FAZ-X was found to be $43.61 \mathrm{mg} / \mathrm{g}$ at $75^{\circ} \mathrm{C}$. Further, adsorption studies at different temperatures were conducted for both these adsorbents to confirm whether functionalization really improves $\mathrm{CO}_{2}$ uptake of zeolite. Adsorption is a temperature-dependent phenomenon and therefore, the performance of FAZ-AMP25 was evaluated at different temperatures in the range $30^{\circ} \mathrm{C}, 55^{\circ} \mathrm{C}, 75^{\circ} \mathrm{C}$ and $120^{\circ} \mathrm{C}$.
Figure $4 a$ displays the breakthrough adsorption curves for FAZ-X and FAZ-AMP25 at different temperatures. The adsorbents were first pretreated in helium flow of $20 \mathrm{ml} / \mathrm{min}$ at $140^{\circ} \mathrm{C}$ for $6 \mathrm{~h}$ to remove any pre-adsorbed gases, and then were subjected to $15 \% \mathrm{CO}_{2} / \mathrm{N}_{2}$ mixture. It was observed that the adsorption capacity of FAZ-X at $30^{\circ} \mathrm{C}, 55^{\circ} \mathrm{C}$ and $75^{\circ} \mathrm{C}$ and $120^{\circ} \mathrm{C}$ was $78.50,55.24,43.61$ and $31.98 \mathrm{mg} / \mathrm{g}$ respectively. It is clearly observed that adsorption efficiency gradually decreases with increasing temperature for FAZ-X, since at higher temperatures surface energy as well as molecular diffusion rates increase resulting in a drastic decrease in the adsorption capacity. On the other hand, adsorption capacity of FAZ-AMP25 increases from $30^{\circ} \mathrm{C}$ to $55^{\circ} \mathrm{C}$, and then decreases at $75^{\circ} \mathrm{C}$ and $120^{\circ} \mathrm{C}$ respectively, and its $\mathrm{CO}_{2}$ adsorption capacity was observed to be $66.87,87.22,52.33$ and $40.7 \mathrm{mg} / \mathrm{g}$ at $30^{\circ} \mathrm{C}, 55^{\circ} \mathrm{C}, 75^{\circ} \mathrm{C}$ and $120^{\circ} \mathrm{C}$ respectively. Enhanced capacity at $55^{\circ} \mathrm{C}$ can be due to chemisorptions, in addition to physisorption at higher temperatures. However, at $75^{\circ} \mathrm{C}, \mathrm{CO}_{2}$ adsorption capacity decreases, which could be due to decrease in chemical interactions and van der Waals force among functionalized adsorbents and the $\mathrm{CO}_{2}$ molecule. Similar observations were also reported by Su et al. ${ }^{20}$ for TEPA (tetraethylenepentamine) functionalized zeolite $\mathrm{Y}$. Thus, optimum adsorption temperature for $\mathrm{FAZ}-\mathrm{AMP} 25$ was found to be $55^{\circ} \mathrm{C}$.

Flue gas stream consists of a definite amount of moisture, and adsorption capacity of most of the zeolites is found to decrease in the presence of moisture. The influence of moisture was studied by subjecting the adsorbent to a simulated flow comprising the gas mixture $15 \% \mathrm{CO}_{2}$, $10 \% \mathrm{H}_{2} \mathrm{O}$ balanced by nitrogen; this was introduced at a flow rate of $20 \mathrm{ml} / \mathrm{min}$. Figure $4 d$ represents the effect of moisture on the adsorption capacity of FAZ-X and FAZAMP25. Adsorption capacity of bare FAZ-X decreased in the presence of moisture; however, it showed a positive effect on FAZ-AMP25. $\mathrm{CO}_{2}$ adsorption-desorption isotherms were obtained at $0^{\circ} \mathrm{C}$ in the pressure range 0 to 1 bar. This was to check the regeneration capability of the adsorbents. It was observed that adsorption capacity was higher at $0^{\circ} \mathrm{C}$ than at elevated temperature. It was also observed that equilibrium adsorption capacity for FAZ-X was better than that of FAZ-AMP 25 at $0^{\circ} \mathrm{C}$. However, at this low temperature, desorption was almost complete for both FAZ-X and FAZ-AMP25 (Figure 4 b). Regeneration of adsorbent is a chief condition for its practical applications. Keeping this in view, a multi-cycle experiment was performed at $55^{\circ} \mathrm{C}$ in a binary mixture of $\mathrm{CO}_{2}$ and $\mathrm{N}_{2}$. Total flow rate was maintained at $20 \mathrm{ml} / \mathrm{min}$ during adsorption and desorption was carried out in a nitrogen flow of $20 \mathrm{ml} / \mathrm{min}$ at $140^{\circ} \mathrm{C}$. Figure $4 c$ shows the multicycle adsorption-desorption curves of FAZ-X and FAZAMP25. The adsorption capacity of FAZ-X decreased after the first cycle of adsorption; however it showed a constant value during the next four cycles (Table 1). For FAZ-AMP25, adsorption capacity was found to decrease 
(a)

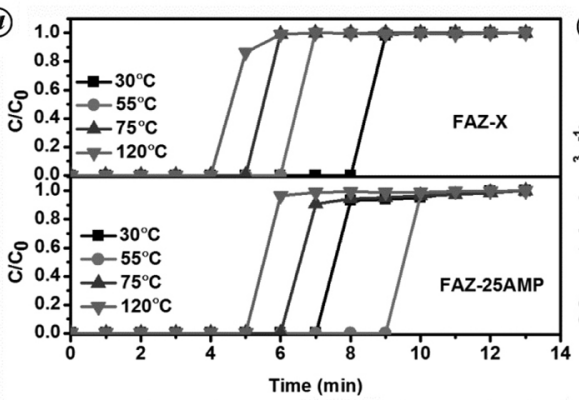

$55^{\circ} \mathrm{C} 140^{\circ} \mathrm{C}$ Cooling to $55^{\circ} \mathrm{C}$

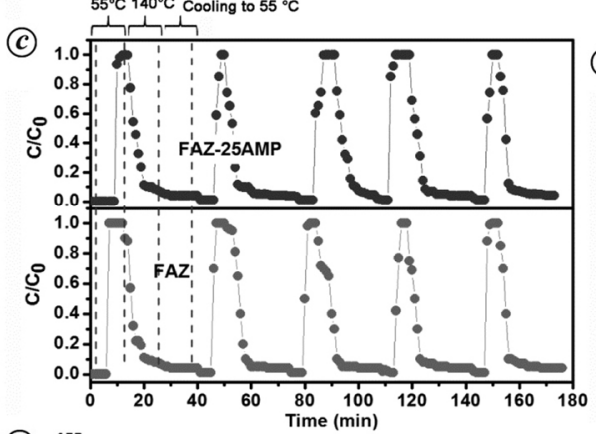

(e)
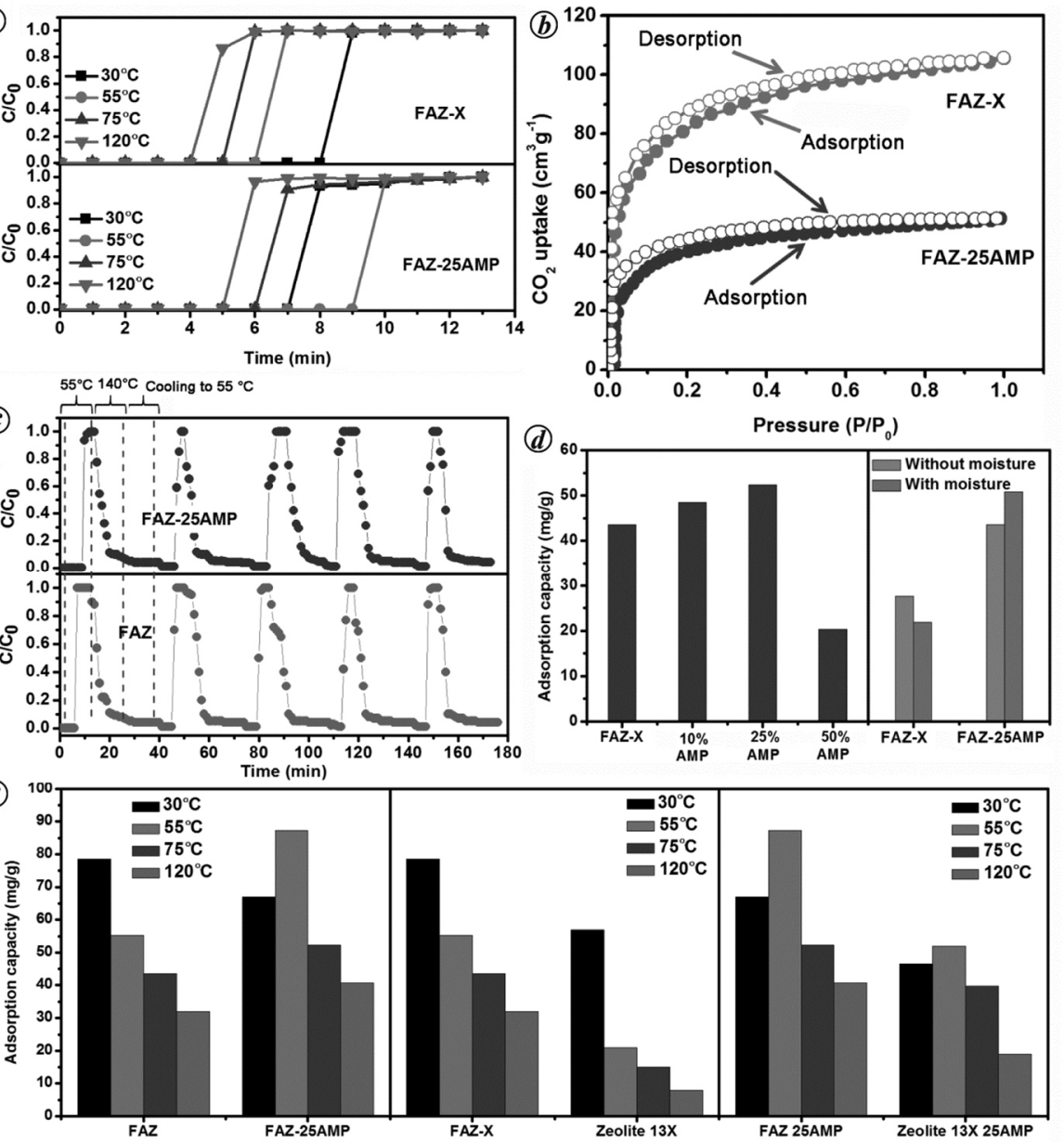

$120^{\circ} \mathrm{C}$

Figure 4. $\boldsymbol{a}$, Breakthrough curves of FAZ-X and FAZ-AMP25 at different temperatures. $\boldsymbol{b}$, Equilibrium adsorption study of FAZ-X and FAZ-AMP 25 at $0^{\circ} \mathrm{C}$. $c$, Multicycle adsorption-desorption study of FAZ-X and FAZAMP25. $\boldsymbol{d}$, Effect of AMP loading on adsorption performance of FAZ-X and effect of moisture on adsorption performance of FAZ-X and FAZ-AMP 25 at $55^{\circ} \mathrm{C}$. $e$, Equilibrium adsorption study of FAZ-X and FAZ-AMP25 at $55^{\circ} \mathrm{C}$. Comparison of zeolite $13 \mathrm{X}$ with FAZ-X and $13 \mathrm{X}$ AMP with FAZ-AMP25 at different temperatures.

Table 1. Breakthrough adsorption capacities in multi-cycle experiments for FAZ and FAZ-AMP

\begin{tabular}{lccccc}
\hline No. of cycles & First & Second & Third & Fourth & Fifth \\
\hline Adsorption capacity FAZ $(\mathrm{mg} / \mathrm{g})$ & 55.24 & 43.6 & 43.5 & 43.7 & 43.2 \\
FAZ-AMP25 $(\mathrm{mg} / \mathrm{g})$ & 87.22 & 52.33 & 40.7 & 40.1 & 40.2 \\
\hline
\end{tabular}

in the first two cycles and then become constant (Table $1)$. The lower regeneration in case of FAZ-AMP25 is mainly due to chemisorption at $55^{\circ} \mathrm{C}$, because of which chemisorbed $\mathrm{CO}_{2}$ could not be regenerated in the second and third cycles; but after the third cycle, adsorption capacity became constant. $\mathrm{CO}_{2}$ adsorption capacities of FAZ-X and FAZ-AMP25 were compared with zeolite $13 \mathrm{X}$ from E-Merck having the BET surface area $359 \mathrm{~m}^{2} / \mathrm{g}$ and functionalized $13 \mathrm{X}$ (13XAMP25) respectively at different adsorption temperatures of $30^{\circ} \mathrm{C}, 55^{\circ} \mathrm{C}, 75^{\circ} \mathrm{C}$ and $120^{\circ} \mathrm{C}$. Figure $4 e$ shows results of the comparison. It can be observed from the $\mathrm{CO}_{2}$ adsorption capacities at different temperatures that though the surface areas of both the zeolites are comparable, adsorption capacities at all the temperatures for fly ash-based zeolites are higher than that of commercial zeolite $13 \mathrm{X}$. At higher temperatures of $75^{\circ} \mathrm{C}$ and $120^{\circ} \mathrm{C}$, adsorption capacities of FAZ-X were almost three times compared to zeolite $13 \mathrm{X}$. Higher adsorption capacity in fly ash-based zeolites could be due to possible functionalization rendered through chemical composition of precursors used for synthesis. Similar results were also reported for functionalized 13X (13X AMP25) and FAZ-AMP25.

Low-cost zeolite $\mathrm{X}$ was successfully synthesized from fly ash of a thermal power plant and functionalized with sterically hindered amine (AMP). Synthesized zeolite showed structural details corresponding to zeolite $\mathrm{X}$ (Linde $\mathrm{X}$ ), as confirmed by powder XRD analysis. 
Functionalization of synthesized zeolite was done with the sterically hindered AMP. This facilitated the adsorption of $\mathrm{CO}_{2}$ at higher temperatures and also improved adsorption capacity in the presence of moisture, which is otherwise a major concern in case of zeolite for flue gas stream from power plants. Regeneration studies revealed that the adsorption capacity decreased after the second cycle of adsorption. Efforts must now be taken to improve regeneration in the later cycles of adsorption in further research.

Declaration. The authors declare no competing financial interests.

1. https://www.esrl.noaa.gov/gmd/ccgg/trends/ (assessed on 4 June 2019).

2. Luthi, D. et al., High-resolution carbon dioxide concentration record 650,000-800,000 years before present. Nature, 2008, 453, 379-382.

3. Herzog, H. J., Scaling up carbon dioxide capture and storage: from megatons to gigatons. Energ. Econ., 2011, 33, 597-604.

4. Lee, Z. H., Lee, K. T., Bhatia, S. and Rahman, A. M., Postcombustion carbon dioxide capture: evolution towards utilization of nanomaterials. Renew. Sust. Energ. Rev., 2012, 16, 2599-2609.

5. Lee, M. G., Yi, G., Ann, B. J. and Roddick, F., Conversion of coal fly ash into zeolite and heavy metal removal. Korean J. Chem. Eng., 2000, 17, 325-331.

6. Ahmed, M. A., Shahnawaz, M., Siddiqui, M. F. and Khan, Z. H., A statistical review on the current scenario of generation and utilization of fly ash in India. Int. J. Curr. Eng. Technol., 2014, 4, 2434-2438.

7. Adamczyk, Z. and Bialecka, B., Hydrothermal synthesis of zeolites from polish coal fly ash. Pol. J. Environ. Stud., 2005, 14, 713-719.

8. Ma, W., Brown, P. W. and Komarneni, S., Characterization and cation exchange properties of zeolite synthesized from fly ashes. J. Mater. Res., 1998, 13, 3-7.

9. Shigemoto, N. and Hayashi, H., Selective formation of $\mathrm{Na}-\mathrm{X}$ zeolite from coal fly ash by fusion with sodium hydroxide prior to hydrothermal reaction. J. Mater. Sci., 1993, 28, 4781-4786.

10. Rayalu, S. S., Udhoji, J. S., Munshi, K. N. and Hasan, M. Z., Highly crystalline zeolite A from fly ash of bituminous and lignite coal combustion. J. Hazard. Mater., 2001, 88, 107-121.

11. Rayalu, S., Meshram, S. U. and Hasan, M. Z., Highly crystalline faujasitic zeolite from fly ash. J. Hazard. Mater., 2000, 77, 123131

12. Dindi, A., Quang, D. and Abu-Zahra, M. R. M., $\mathrm{CO}_{2}$ adsorption testing on fly ash derived cancrinite-type zeolite and its aminefunctionalized derivatives. Environ. Prog. Sust. Energ., 2019, 38, 77-78.

13. Belviso, C., State-of-the-art applications of fly ash from coal and biomass: a focus on zeolite synthesis processes and issues. Prog. Energ. Combust. Sci., 2018, 65, 109-135.

14. Oliveira, J. A., Cunha, F. A. and Ruotolo, L. A. M., Synthesis of zeolite from sugarcane bagasse fly ash and its application as a low-cost adsorbent to remove heavy metals. J. Clean. Prod., 2019, 229, 956-963.

15. Dindi, A., Quang, V. D., Vega, L. F., Nashef, E. and Abu-Zahra, M. R. M., Applications of fly ash for $\mathrm{CO}_{2}$ capture, utilization, and storage. J. $\mathrm{CO}_{2}$ Util., 2019, 29, 82-102.

16. Bougie, F. and Iliuta, M. C., Sterically hindered amine-based absorbents for the removal of $\mathrm{CO}_{2}$ from gas streams. J. Chem. Eng. Data, 2012, 57, 635-669.
17. Kim, W., Chae, W., Kwon, S., Kim, K., Lee, H. and Kim, S., Effect of dry grinding of pyrophyllite on the hydrothermal synthesis of zeolite Na-X and Na-A. Mater. Trans. JIM, 2014, 55, 14881493.

18. Hui, H., Gao, J., Wang, G., Liu, P. and Zhang, K., Effects of $\mathrm{Na}$ and $\mathrm{K}$ ions on the crystallization of low silica $\mathrm{X}$ zeolite and its catalytic performance for alkylation of toluene with methanol. $J$. Braz. Chem. Soc., 2014, 25, 65-74.

19. Sing, K. S. W., Everett, D. H., Haul, R. A. W., Moscou, L., Pierotti, R. A., Rouquerol, J. and Siemieniewska, T., Reporting physisorption data for gas/solid systems with special reference to the determination of surface area and porosity. Pure Appl. Chem., 1985, 57, 603-619.

20. Su, F., Lu, C., Kuo, S. C. and Zeng, W., Adsorption of $\mathrm{CO}_{2}$ on amine-functionalized Y-type zeolites. Energ. Fuel, 2010, 24, $1441-1448$.

ACKNOWLEDGEMENTS. We thank the Director, CSIR-NEERI, Nagpur for providing research facilities, and the International Scientific Partnership Program at King Saud University, Riyadh for funds through ISPP\# 0057 Grant (CSIR-NEERI/KRC/2019/JUNE/EMD-ERMD/1).

Received 9 August 2019; revised accepted 20 May 2020

doi: $10.18520 / \mathrm{cs} / \mathrm{v} 119 / \mathrm{i} 1 / 123-128$

\section{Landsat 8-based surface temperature anomaly and hydrocarbon prospectivity: a study in part of Assam-Arakan Fold Belt, North East India}

\author{
Santosh Garain ${ }^{1}$, Debashis Mitra ${ }^{2}$ and \\ Pranab Das ${ }^{3, *}$
}

${ }^{1}$ Oil and Natural Gas Corporation Limited, Assam-Arakan Fold Belt Exploratory Asset, Silchar 788 026, India

${ }^{2}$ Indian Institute of Remote Sensing, 4, Kalidas Road,

Dehradun 248 001, India

${ }^{3}$ Department of Applied Geology, Indian Institute of Technology (Indian School of Mines), Dhanbad 826 004, India

Subsurface hydrocarbon reservoirs act as effective thermal barriers to the Earth's heat flow from the interior to the surface. As a result, a positive thermal anomaly below a hydrocarbon reservoir and a negative thermal anomaly on the surface above the reservoir are observed. The use of remote sensing satellite images is a rapid, cost-effective and accurate method of determining land surface temperature of a region. The present study uses recent Landsat 8 operational

*For correspondence. (e-mail: pranab@iitism.ac.in) 